\title{
Overexpression of VEGF and Angiopoietin 2: A Key to High Vascularity of Hepatocellular Carcinoma?
}

Woo Sung Moon, M.D., Ph.D., Ki Hoon Rhyu, M.Sc., Myoung Jae Kang, M.D., Ph.D., Dong Geun Lee, M.D., Ph.D., Hee Chul Yu, M.D., Ph.D., Jung Ho Yeum, M.D., Gou Young Koh, M.D., Ph.D., Andrzej S. Tarnawski, M.D., D.Sc.

Departments of Pathology (WSM, KHR, MJK, DGL), General Surgery (HCY), Preventive Medicine (JHY), and Institute for Medical Sciences, Chonbuk National University, Medical School, Chonju, Korea; Pohang University of Science and Technology (GYK), Pohang, Korea; and Department of Medicine, Veterans Administration Medical Center, Long Beach, and Division of Gastroenterology, the University of California, Irvine, California (AST)

Hepatocellular carcinoma (HCC) is becoming one of the most common malignant tumors worldwide and is characterized by a high vascularity. Angiogenesis, formation of new microvessels, is critical for the growth and progression of various human solid tumors. Vascular endothelial growth factor (VEGF) and angiopoietins (Ang1 and Ang2) are endothelial cell-specific vasculogenic and angiogenic growth factors, but their expression and roles in HCC have not been extensively explored. The aim of this study was to determine the expression and cellular localization of VEGF, Ang1, and Ang2 in specimens of resected human HCC using in situ hybridization and immunohistochemical staining and to examine their relationship to microvessel density (MVD) and tumor size. We also investigated whether mutation of p53 protein might affect the expression of the above angiogenic growth factors. VEGF and Ang2 were strongly expressed and localized predominantly to cancer cells, whereas Ang1 was detected in supportive cells of large blood vessels, stromal cells, endothelial cells, and tumor cells. Expression of the VEGF protein and the Ang2 (but not Ang1) mRNA were strongly correlated with MVD $(P<.05, P=.001)$ and tumor size $(P<.05)$. There was also a strong correlation between VEGF protein and Ang2 mRNA expression $(P<.001)$. However, no significant correlation was found between overexpression of p53 and the expression of VEGF, angiopoietins, or MVD. These findings suggest that overproduction of the angiogenic growth factors VEGF

Copyright () 2003 by The United States and Canadian Academy of Pathology, Inc.

VOL. 16, NO. 6, P. 552, 2003 Printed in the U.S.A.

Date of acceptance: February 21, 2003.

Address reprint requests to: Andrzej S. Tarnawski, M.D., D.Sc., Veterans

Administration Medical Center, 5901 East Seventh Street, Long Beach, CA

90822; fax: 562-961-8016; e-mail: atarnawski@yahoo.com.

DOI: 10.1097/01.MP.0000071841.17900.69 and Ang2 by HCC cells may increase vascularity and tumor growth in a paracrine manner. Our findings also suggest that interaction between VEGF and Ang2 may play a critical role in tumor angiogenesis in HCC.

KEY WORDS: Angiogenesis, Angiopoietin, Hepatocellular carcinoma, P53, Vascular endothelial growth factor.

Mod Pathol 2003;16(6):552-557

Hepatocellular carcinoma (HCC) is a highly vascular tumor, and this increased vascularity can lead to tumor rupture (1). Angiogenesis, formation of new microvessels, is critical for the growth and progression of various human solid tumors because it enables delivery of oxygen and nutrients (2). Angiogenesis is regulated by angiogenic factors, such as vascular endothelial growth factor (VEGF) and angiopoietins, which can be secreted by some tumor cells (3). Among the known angiogenic factors, VEGF has emerged as the central regulator of the angiogenic process in physiological and pathological conditions. VEGF, also known as vascular permeability factor, stimulates the proliferation of endothelial cells through specific tyrosine kinase receptors, flt- 1 and flk/KDR (2-4), expressed almost exclusively on endothelial cells. Recently, a new family of growth factors, the angiopoietins, which also are specific for the vascular endothelium, have been identified. They are ligands for the tyrosine kinase receptor Tie2 (tyrosine kinase containing immunoglobulin-like loop and epidermal growth factor-like domain; 5-7). Angiopoietin 1 (Ang1) serves as a survival factor for the endothelium and promotes recruitment of pericytes and smooth muscle cells, thereby serving to stabilize vascular networks $(8,9)$. Angiopoietin 2 (Ang2) is a biological antagonist of Ang1 and is dramatically expressed at 
sites of vascular remodeling. It reduces vascular stability and facilitates access of VEGF to endothelial cells $(10,11)$.

The p53 tumor suppressor regulates the cell cycle and DNA repair and synthesis, as well as programmed cell death (apoptosis; 12). The p53 gene is the most commonly mutated gene in human cancers $(12,13)$, including HCC. The wild-type p53 gene has been shown to suppress angiogenesis via regulation of thrombospondin 1 (14), and mutated p53 genes have been shown to be potent stimulators of VEGF induction in NIH 3T3 cells (15). These findings suggest that mutant p53 provides a preferential advantage to tumor growth, not only by allowing tumor cells to escape apoptosis but also by inducing increased vascularization.

To date, there have been only a few studies concerning the relationship between the expression of VEGF and the angiopoietins and angiogenesis in HCC. In this study, we investigated the correlation between angiogenesis and the expression of angiogenic factors, Ang1, Ang2, and VEGF, determined by in situ hybridization and immunohistochemistry, in resected human HCC specimens. We also examined whether mutation of p53 would affect the expression of these angiogenic factors.

\section{MATERIALS AND METHODS}

\section{Patients and Specimens}

This study was approved by the Human Ethics Committee of Chonbuk National University Medical School, Korea. We studied, retrospectively, HCC specimens obtained from 49 patients who underwent surgical resection between 1990 and 1999 at the Chonbuk National University Hospital. Of the 49 patients with HCC, 37 were men and 12 were women. The mean age of the patients was 54 years (range, 29-76 y). HBV and HCV serologies were positive in 31 and 5 patients, respectively.

\section{In Situ Hybridization for Angiopoietin 1 and Angiopoietin 2}

Human Ang1 and Ang2 mRNA detection was performed using in situ hybridization. For this, paraffin-embedded sections and digoxigeninlabeled anti-sense RNA probes were used. Human Ang1 and Ang2 probes were generated from linearized pBluescript II KS+ plasmids (Stratagene, La Jolla, CA) that contain a HindIII-EcoRI fragment corresponding to nucleotides 396 through 809 of the human angiopoietin-1 cDNA, and a XhoIBamHI fragment corresponding to nucleotides 638 through 920 of the human angiopoietin-2 cDNA, respectively. Digoxigenin-labeled RNAs were synthesized using a DIG RNA Labeling kit (Boehringer
Mannheim, Indianapolis, IN). Sections were preincubated in mRNA in situ hybridization solution (DAKO, Carpenteria, CA). Hybridization was carried out overnight at $55^{\circ} \mathrm{C}$ in a humidified chamber. The concentration of the hybridization mixture was 0.5 ng RNA of probe per $1 \mu \mathrm{L}$ of the mRNA in situ hybridization solution used for the prehybridization step. The posthybridization wash was performed at $53^{\circ} \mathrm{C}$ in $0.1 \times$ stringent wash solution (DAKO). After blocking the nonspecific protein binding, the mRNA signals were detected using anti-digoxigenin/alkaline phosphatase (DIG-AP) antibody and bromochloroindoylphosphate-nitrobluetetrazolium (BCIP-NBT) chromogen substrate (DAKO). A sense probe was used as a negative control.

\section{Immunohistochemistry}

The immunoperoxidase method, using the streptavidin-biotinylated horseradish peroxidase complex (DAKO), was carried out. Sections $4 \mu \mathrm{m}$ thick were cut from formalin-fixed, paraffinembedded tissue blocks. After deparaffinization, the sections were incubated in methanol containing $0.3 \%$ hydrogen peroxide at room temperature for 30 minutes to block endogenous peroxidase and were treated with a microwave antigen retrieval procedure in 0.01 м sodium citrate buffer ( $\mathrm{pH}$ 6.0; for p53 immunostaining), with proteinase K (DAKO; for VEGF immunostaining) for 10 minutes, or with target retrieval solution (DAKO) for 20 minutes at $97^{\circ} \mathrm{C}$ (for angiopoietin 1 and angiopoietin $2 \mathrm{immu}$ nostaining). After blocking endogenous biotin, the sections were incubated with Protein Block Serum Free Solution (DAKO) at room temperature for 10 minutes, to block nonspecific staining, and were then incubated for 2 hours at room temperature with either anti-p53 antibody (Oncogene Science, Uniondale, NY) or anti-CD34 antibody (Novocastra, Newcastle, UK) or were incubated overnight at $4^{\circ} \mathrm{C}$ with anti-VEGF (Santa Cruz Biotechnology, Santa Cruz, CA) and anti-angiopoietin1 and -2 (Chemicon international, Temecula, CA) as primary antibodies. After washing, the sections were incubated with a biotin-conjugated secondary antibody at room temperature for 30 minutes and finally with peroxidase conjugated streptavidin at room temperature for 30 minutes. Peroxidase activity was detected with the enzyme substrate, 3 amino-9-ethyl carbazole. For negative controls, sections were treated the same way except they were incubated with Tris buffered saline instead of the primary antibody. Samples with staining of $\geq 10 \%$ of the tumor cells were defined as positive, and the intensity of immunoreactivity was graded as weak $(+)$, moderate $(++)$, and strong $(+++)$. Cells showing nuclear staining for p53 were considered positive. 


\section{Quantification of Microvessel Density}

We used an image analysis system (Soft Imaging System $\mathrm{GmbH}$ ) to measure the total area of all stained endothelial cells. Because the immunoreactivity of CD34 showed heterogeneity within the same tumor, the four most highly vascularized areas were selected for measurements performed under $200 \times$ magnification. MVD was expressed as the percentage of the total CD34-stained area (endothelial cells of sinusoid and portal blood vessels in tumor) per total evaluated section area (16).

\section{Statistical Analysis}

The comparison between expression of Ang1, Ang2 mRNA, VEGF protein, p53 protein, and MVD was made using Student's $t$ test. Associations between the expression of Ang1, Ang2 mRNA, VEGF protein, and p53 protein and tumor size were tested by the $\chi^{2}$ test. Results are reported as mean \pm SD for MVD. A $P$ value of $<.05$ was considered significant.

\section{RESULTS}

\section{Angiopoietin 1 and 2 mRNA Localization}

Ang1 mRNA was expressed in 34 of 49 specimens (69\%), and Ang2 was expressed in 22 of 49 speci- mens (45\%). Both Angl and 2 mRNA were expressed in 19 (39\%) of the specimens, whereas 12 (24\%) specimens showed neither Ang1 nor Ang2 mRNA expression. Ang1 and 2 mRNA were predominantly expressed in HCC cells, with intense labeling of the cytoplasm. No or only minimal staining was present in hepatocytes of both normal and cirrhotic liver outside of the tumors (Fig. 1A). The Ang2 mRNA was also expressed in some of the sinusoidal endothelial cells in both tumor and nonmalignant liver tissue. In addition to the tumor cells, Ang1 mRNA was also present in the smooth muscle cells of large blood vessels and in stromal cells, as well as in endothelial cells of both HCC and non-malignant liver tissue (Fig. 1B). Ang1 mRNA was strongly expressed in cancer cells surrounding the tumoral vessels (Fig. 1C). In some tumors, Ang2 mRNA was predominantly expressed in the telangiectatic sinusoids (Fig. 1D). No specific labeling was found using the control sense probe.

\section{Immunohistochemistry for VEGF, P53, CD34, Ang1, and 2}

Immunohistochemical staining for p53 was positive in 17 of 49 tumors (35\%). In all positive cases, the staining was nuclear. Among them, 11 were scored as,+ 3 as ++ , and the remaining 3 as +++ .

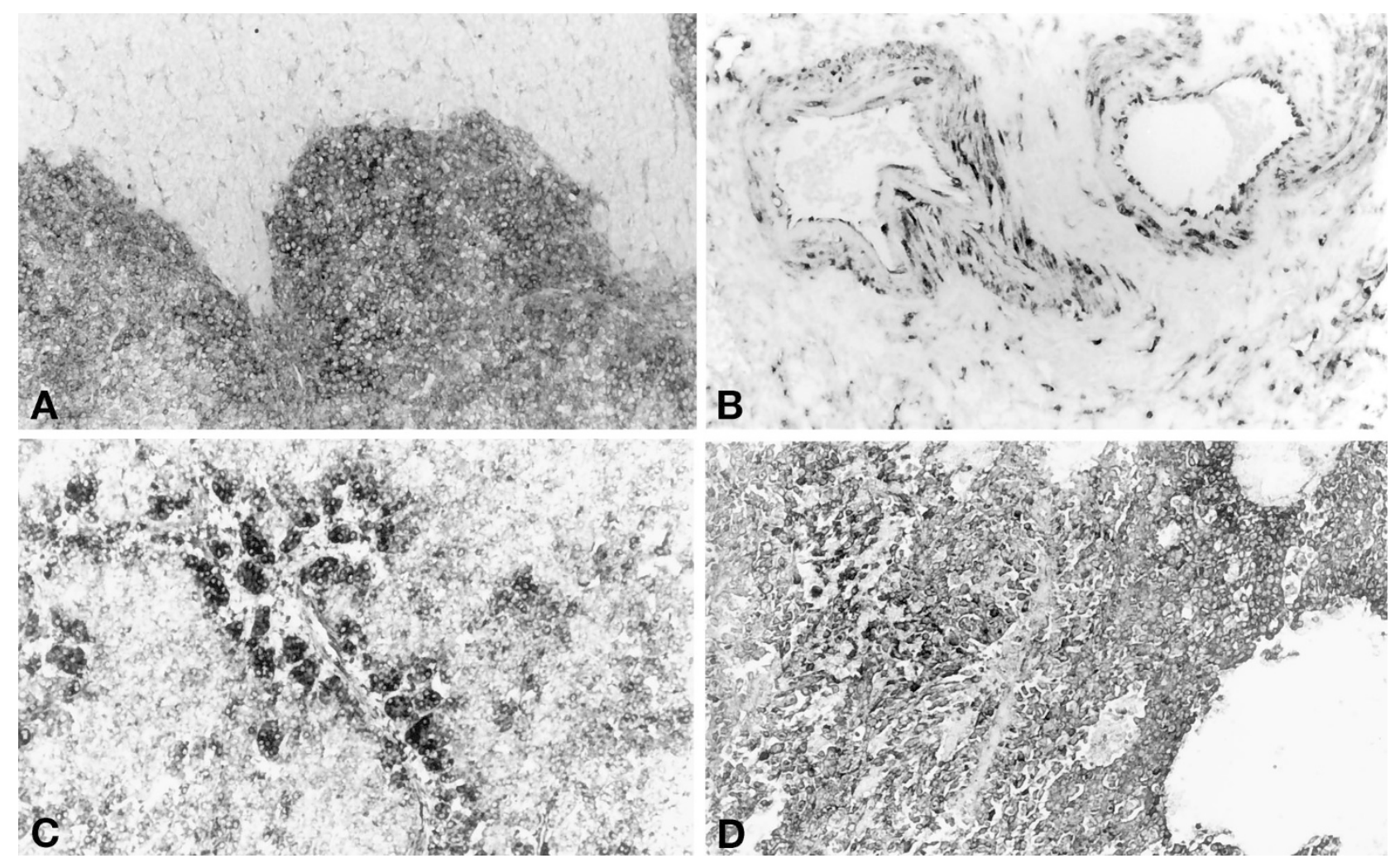

FIGURE 1. In situ hybridization for angiopoietin1 and -2 mRNAs. A. Ang2 mRNA expression in infiltrating tumor cells (black signals) with no staining on adjacent nontumorous hepatocytes (Ang2, 100×). B, expression of Ang1 mRNA in endothelial cells, smooth muscle cells of large vessel and stromal cells (black signals; Ang1, 200×). C, strong cytoplasmic staining for Ang1 mRNA in tumor cells (black signals) surrounding tumor vessels (Ang1, 100×). D, strong positive reaction for Ang2 mRNA in tumor cells in area of telangiectatic sinusoidal lesion (100 $\times$ ). 
CD 34 was expressed in the endothelium lining the sinusoids in tumor tissue but not in normal liver tissue. Cirrhotic nodules showed a focal, peripheral pattern of sinusoidal CD34 expression. The microvessel density of the HCC tumors ranged from 0.1 to $16.3 \%$, with an average $4.7 \pm 3.1 \%$. VEGF expression was detected in 38 of 49 specimens (77\%). In 19 tumors, the intensity of staining was graded as + , whereas 12 tumors were graded as ++ , and 7 tumors were graded as +++ . The VEGF immunoreactivity was localized to the cytoplasm of the cancer cells. In some instances, VEGF staining at the boundary of the tumor was higher than in the center of tumor. VEGF signals were also present in both hepatocytes of cirrhotic and normal liver, but VEGF expression was considerably less intense in these cells than that of HCC. We selected the 10 representative HCC specimens with strong Angl and Ang2 mRNA expression and performed immunostaining for Ang1 and 2 proteins to examine and compare localization of proteins and mRNAs. Immunostaining with polyclonal antibodies specific for human Ang1 and 2 showed that localization of Ang1 and Ang2 proteins and respective Ang1 and Ang2 mRNA was very similar in all specimens (Fig. $2 \mathrm{~A}, \mathrm{~B})$.

\section{Statistical Results}

The specimens showing positive Ang2 mRNA expression in tumor cells had a significantly higher MVD than did those absent of Ang-2 mRNA expression $(P=.001)$. VEGF-positive tumors showed a significantly higher MVD than VEGF negative tumors $(P<.05)$. Ang1 mRNA expression and p53 overexpression did not have any significant correlation with MVD (Table 1). Co-expression of VEGF protein and Ang2 mRNA was present in 19 of 49
TABLE 1. Correlation of Microvessel Density (Expressed as Percentage of the Total Microvessel Area Per Area of Four $\times \mathbf{2 0 0}$ Microscopic Fields) and the Expression of Angiogenic Growth Factors

\begin{tabular}{lccc}
\hline & $\begin{array}{c}\text { Number of HCC } \\
\text { Specimens }\end{array}$ & $\begin{array}{c}\text { MV area \% } \\
\text { (Mean } \pm \text { SD\%) } \\
\text { in Tumor }\end{array}$ & Significance \\
& & & \\
\hline $\begin{array}{l}\text { Angiopoietin 1 mRNA } \\
\quad \text { Positive }\end{array}$ & 34 & $4.8 \pm 3.3$ & 0.523 \\
$\quad$ Negative & 15 & $4.2 \pm 2.4$ & \\
Angiopoietin 2 mRNA & & & \\
$\quad$ Positive & 22 & $6.2 \pm 3.6$ & 0.001 \\
$\quad$ Negative & 27 & $3.4 \pm 1.9$ & \\
VEGF protein & & & 0.029 \\
$\quad$ Positive & 38 & $5.2 \pm 3.2$ & 0.932 \\
$\quad$ Negative & 11 & $2.9 \pm 1.7$ & \\
P53 protein & & $4.6 \pm 3.8$ & \\
$\quad$ Positive & 17 & $4.7 \pm 2.6$ & \\
$\quad$ Negative & 32 &
\end{tabular}

cases (38\%). A strong correlation was found between VEGF protein and Ang2 mRNA expression ( $P$ $<$.001). There was no significant correlation between Ang1, Ang2 mRNA, or VEGF expression and p53 overexpression. VEGF proteins expression and the expression of Ang2 mRNA significantly correlated with tumor size (Table 2).

\section{DISCUSSION}

Our study demonstrates that the expression of VEGF in HCC, together with the expression of Ang2, is correlated with increased MVD of tumors and with tumor size. We also found a significant correlation between the expression of Ang2 mRNA and VEGF protein. However, expression of these angiogenic factors and MVD appeared to be independent of p53 expression. Although the importance of angiopoietins in embryonic angiogenesis has been clearly delineated $(5,6,17)$, their role in tumor

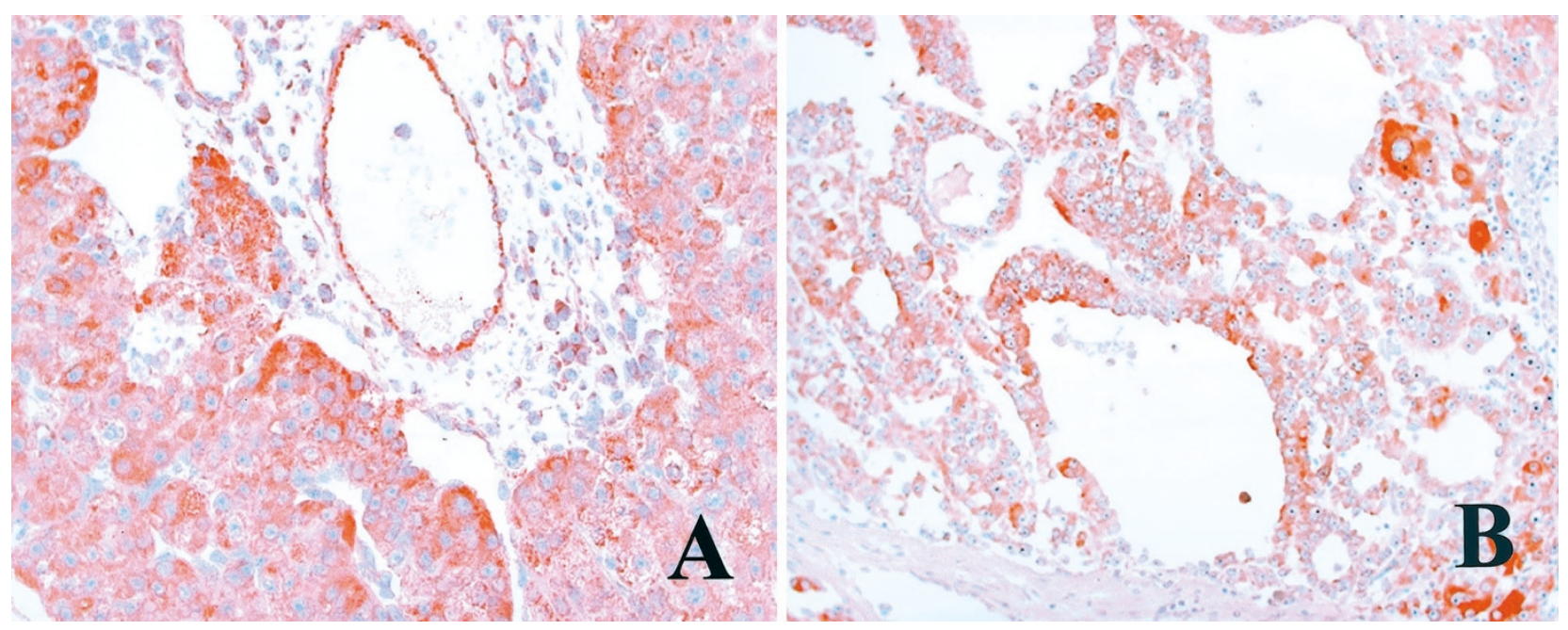

FIGURE 2. Immunohistochemistry for angiopoietinl and -2 proteins. A, consistent with in situ hybridization result, Angl was strongly expressed in tumor cells surrounding tumor vessel (Ang1, 100×). B, Ang2 protein was strongly expressed in tumor cells of dilated sinusoidal area (Ang2, 100 $\times$ ). 
TABLE 2. Correlation between Expression of VEGF, or Angiopoietin 2 and Tumor Size

\begin{tabular}{cccc}
\hline & $\begin{array}{c}\geq 2 \mathrm{~m} \text { in } \\
\text { Tumor Size }\end{array}$ & $\begin{array}{c}<2 \mathrm{~cm} \text { in } \\
\text { Tumor Size }\end{array}$ & $\begin{array}{c}\text { Total } \\
\text { Number }\end{array}$ \\
\hline$P=.04$ & & & \\
VEGF positive & $32(65.3 \%)$ & $6(12.2 \%)$ & 38 \\
VEGF negative & $6(12.2 \%)$ & $5(10.2 \%)$ & 11 \\
Total number & 38 & 11 & 49 \\
$P=.03$ & & & \\
Ang 2 positive & $20(40.8 \%)$ & $2(4.0 \%)$ & 22 \\
Ang 2 negative & $18(36.7 \%)$ & $9(18.3 \%)$ & 27 \\
Total number & 38 & 11 & 49 \\
\hline
\end{tabular}

angiogenesis has not been well explored. Previous studies have demonstrated that Angl expression persists widely in adult tissue, whereas Ang2 appears to be selectively expressed only at sites of active vascular remodeling, such as the uterus, ovaries, and placenta $(6,8,10)$. This indicates that the main role of Ang1 is maintenance and stabilization of the vasculature, whereas Ang2 is required for vascular remodeling during angiogenesis. Our finding that the Ang1 was present in endothelial, stromal mesenchymal, and smooth muscle cells of large blood vessels of non-malignant liver tissue, in addition to tumor cells, supports the contention that Ang1 is expressed in normal adult tissue, where it likely functions to stabilize blood vessels. It has been postulated that local activation of the Ang2 gene, resulting in overexpression of Ang2, blocks Ang1-mediated Tie2 receptor signaling and causes loosening of tight vascular structures, which results in exposure of endothelial cells to VEGF. Subsequently, VEGF triggers endothelial cell migration, proliferation, sprouting, tube formation and, thus, angiogenesis. Therefore, in the presence of simultaneous VEGF overexpression, local Ang2 expression facilitates the initiation of angiogenesis $(6,10$, 11, 18, 19). Later, when Ang2 expression is reduced and Angl expression is increased, Angl-induced Tie2 receptor activation causes maturation and stabilization of the newly formed vessels and microvessels. In light of these study results, our present results support the contention that Ang2 may facilitate angiogenesis at the site of vascular remodeling in the presence of high VEGF levels.

Recently, Tanaka et al. (20) reported that Ang2 mRNA was overexpressed in hepatocarcinoma cells but was not expressed in adjacent liver tissue and that injection of HCC cells into nude mice that overexpressed Ang2 induced extensive intraperitoneal bleeding and the formation of large tumors. Conversely, they found that Angl was equally expressed in HCC and adjacent non-malignant liver tissue. In our present study, we did not detect strong expression of Ang1 mRNA in adjacent nonmalignant hepatocytes using the in situ hybridization method. This discrepancy may be related to the different methods of detecting of Angl mRNA.
Tanaka et al. (20) analyzed Angl expression using the RT-PCR method, so in that study, inclusion of other tissue components expressing Angl (such as stromal cells, endothelial cells, and smooth muscle cells of vessels in nonmalignant liver tissue) was likely a contributing factor for their findings.

In this study, Angl expression did not correlate with MVD nor with the tumor size. The exact role of Ang1 in tumor angiogenesis is controversial. In a previous study using a breast cancer cell line, overexpression of Ang1 did not promote angiogenesis and did not enhance tumor growth (21). In fact, tumors induced by Ang1-transfected cells were smaller and showed fewer vessels than did those of the Ang2-transfected cells (22). However, some other studies reported that high expression of Ang1 correlated with tumor angiogenesis (23) and that inhibition of Angl expression in HeLa cells suppressed growth of xenografted tumors (24).

Mutation of the tumor suppressor gene p53 triggers tumorigenesis, and some reports showed that this may be due to increased angiogenesis $(14,15)$. A number of studies have shown a relationship between VEGF expression, or angiogenesis and p53 mutation in human tumors. Some studies showed a positive correlative relationship $(25,26)$, but others did not $(27,28)$. However, no study has yet examined the relationship between p53 overexpression and angiopoietin expression in HCC. Our study did not find a statistically significant correlation between p53 expression and the expression of angiopoietins, nor between p53 and MVD in HCC. The data regarding a correlation between p53, or angiogenesis, and prognosis in HCC are contradictory $(29,30)$. Further analysis of the p53 overexpression and MVD in clinical HCC tumor samples might provide useful information regarding prognosis and treatment.

In summary, our study showed an association between overexpression of VEGF and Ang2 in tumor cells, tumor vascularity, and size of human HCC.

\section{REFERENCES}

1. Yeh CN, Lee WC, Jeng LB, Chen MF, Yu MC. Spontaneous tumor rupture and prognosis in patients with hepatocellular carcinoma. Br J Surg 2002;89:1125-9.

2. Leung DW, Carchianes G, Kuang WJ, Goeddel DV, Ferrara N. Vascular endothelial growth factor is a secreted angiogenic mitogen. Science 1989;246:1306-9.

3. Fox SB, Gatter KC, Harris AL. Tumor angiogenesis. J Pathol 1996;179:232-7.

4. Ferrara N, Davis-Smyth T. The biology of vascular endothelial growth factor. Endocr Rev 1997;18:4-25.

5. Suri C, Jones PF, Patan S, Bartunkova S, Maisonpierre PC, Davis S, et al. Requisite role of angiopoietin-1, a ligand for the TIE2 receptor, during embryogenic angiogenesis. Cell 1996;87:1171-80.

6. Maisonpierre PC, Suri C, Jones PF, Bartunkova S, Wiegand S, Radziejewski C, et al. Angiopoietin-2, a natural antagonist for 
Tie-2 that disrupts in vivo angiogenesis. Science 1997;277: 55-80.

7. Valenzuela DM, Griffiths J, Rojas J, Aldrich TH, Jones PF, Zhou H, et al. Angiopoietin 3 and 4: diverging gene counterparts in mouse and man. Proc Natl Acad Sci U S A 1999;96: 4-9.

8. Papapetropoulos A, Garcia-Cardena G, Dengler TJ, Maisonpierre PC, Yancopoulos GD, Sessa WC. Direct actions of angiopoietin-1 on human endothelium: evidence for network stabilization, cell survival, and interaction with other angiogenic growth factors. Lab Invest 1999;79:213-23.

9. Kwak HJ, So JN, Lee SJ, Kim I, Koh GY. Angiopoietin-1 is an apoptosis survival factor for endothelial cells. FEBS Lett 1999;448:249-53.

10. Holash J, Maisonpierre PC, Compton D, Boland P, Alexander $\mathrm{CR}$, Zagzag D, et al. Vessel co-option, regression, and growth in tumors mediated by angiopoietins and VEGF. Science 1999;284:1994-8.

11. Lauren J, Gunji Y, Alitalo K. Is angiopoietin-2 necessary for the initiation of tumor angiogenesis? Am J Pathol 1998;153: 1333-9.

12. Hollstein M, Sidransky D, Vogelstein B, Harris CC. p53 mutation in human cancers. Science 1991;253:49-53.

13. Nigro JM, Baker SJ, Preisinger AC, Jessup JM, Hostetter R, Cleary $\mathrm{K}$, et al. Mutation in the p53 gene occur in diverse human tumor types. Nature 1989;342:705-8.

14. Dameron KM, Volpert OV, Tainsky MA, Bouck N. Control of angiogenesis in fibroblasts by p53 regulation of thrombospondin-1. Science 1994;265:346-55.

15. Kieser A, Weich HA, Brandner G, Marme D, Kolch W. Mutant p53 potentiates protein kinase C induction of vascular endothelial growth factor expression. Oncogene 1994;255:98991.

16. Kimura H, Nakajima T, Kagawa K, Deguchi T, Kakusui M, Katagishi T, et al. Angiogenesis in hepatocellular carcinoma as evaluated by CD34 immunohistochemistry. Liver 1998;18: $14-9$.

17. Dumont DJ, Gradwohl G, Fong GH, Puri MC, Gerenstein M, Auerbach A, et al. Dominant-negative and targeted null mutations in the endothelial receptor tyrosine kinase, tek, reveal a critical role in vasculogenesis of the embryo. Genes Dev 1994;8:1897-909.

18. Bunone G, Vigneri P, Mariani L, Buto S, Collini P, Pilotti S, et al. Expression of angiogenesis stimulators and inhibitors in human thyroid tumors and correlation with clinical pathological features. Am J Pathol 1999;155:1967-76.

19. Stratmann A, Risau W, Plate KH. Cell type-specific expression of angiopoietin-1 and angiopoietin-2 suggests a role in glioblastoma angiogenesis. Am J Pathol 1998;153:1459-66.
20. Tanaka S, Mori M, Sakamoto Y, Makuuchi MN, Sugimachi K, Wands JR. Biologic significance of angiopoietin-2 expression in human hepatocellular carcinoma. J Clin Invest 1999;103: $341-5$.

21. Hayes AJ, Huang WQ, Yu J, Maisonpierre PC, Liu A, Kern FG, et al. Expression and function of angiopoietin-1 in breast cancer. Br J Cancer 2000;83:1154-60.

22. Ahmad SA, Liu W, Jung YD, Fan F, Willson M, Reinmuth N, et al. The effects of angiopoietin-1 and -2 on tumor growth and angiogenesis in human colon cancer. Cancer Res 2001; 61:1255-9.

23. Takahama M, Tsutsumi M, Tsujiuchi T, Vezu K, Kushibe K, Taniguchi S, et al. Enhanced expression of Tie2, its ligand angiopoietin-1 vascular endothelial growth factor, and CD31 in human non-small cell lung carcinoma. Clin Cancer Res 1999;5:2506-10.

24. Shim WSN, The M, Mack POP, Ge R. Inhibition of angiopoietin-1 expression in tumor cells by an antiserum RNA approach inhibited xenograft tumor growth in immunodeficient mice. Int J Cancer 2001;94:6-15.

25. Uchida S, Shimada Y, Watanabe H, Tanaka H, Shibagaki I, Miyahara $\mathrm{T}$, et al. In esophageal squamous cell carcinoma vascular endothelial growth factor is associated with p53 mutation, advanced stage and poor prognosis. Br J Cancer 1998;77:1704-9.

26. Linderholm BK, Lindahl T, Holmberg L, Klaar S, Lennerstrand J, Henriksson R, Bergh J. The expression of vascular endothelial growth factor correlates with mutant p53 and poor prognosis in human breast cancer. Cancer Res 2001; 61:2256-60.

27. Strohmeyer D, Rossing C, Bauerfeind A, Kaufmann O, Schlechte H, Bartsch G, et al. Vascular endothelial growth factor and its correlation with angiogenesis and p53 expression in prostatic cancer. Prostate 2000;45:216-24.

28. Kawahara N, Ono M, Taguchi K, Okamoto M, Shimada M, Takenaka K, et al. Enhanced expression of thrombospondin-1 and hypovascularity in human cholangiocarcinoma. Hepatology 1998;28:1512-27.

29. Ng IO, Fan ST. Is the p53 mutation of prognostic value in hepatocellular carcinoma [letter]? Arch Surg 2000;135:1476.

30. El-Assal ON, Yamanoi A, Soda Y, Yamaguchi M, Igarashi $\mathrm{M}$, Yamamoto A, et al. Clinical significance of microvessel density and vascular endothelial growth factor expression in hepatocellular carcinoma and surrounding liver: possible involvement of vascular endothelial growth factor in the angiogenesis of cirrhotic liver. Hepatology 1998;27: $1554-62$ 